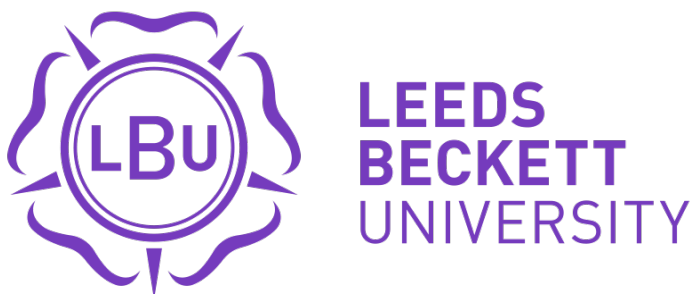

Citation:

Woodall, J (2020) Health promotion co-existing in a high-security prison context : a documentary analysis. International Journal of Prisoner Health. ISSN 1744-9200 DOI: https://doi.org/10.1108/IJPH-09-2019-0047

Link to Leeds Beckett Repository record:

https://eprints.leedsbeckett.ac.uk/id/eprint/6691/

Document Version:

Article (Accepted Version)

Copyright (C) 2020, Emerald Publishing Limited

The aim of the Leeds Beckett Repository is to provide open access to our research, as required by funder policies and permitted by publishers and copyright law.

The Leeds Beckett repository holds a wide range of publications, each of which has been checked for copyright and the relevant embargo period has been applied by the Research Services team.

We operate on a standard take-down policy. If you are the author or publisher of an output and you would like it removed from the repository, please contact us and we will investigate on a case-by-case basis.

Each thesis in the repository has been cleared where necessary by the author for third party copyright. If you would like a thesis to be removed from the repository or believe there is an issue with copyright, please contact us on openaccess@leedsbeckett.ac.uk and we will investigate on a case-by-case basis. 


\title{
Health promotion co-existing in a high-security prison context: a documentary analysis
}

\author{
Abstract \\ Purpose: There is interest in promoting health in prison from governmental levels, but, to date, \\ understanding how best to do this is unclear. This paper argues that nuanced understanding of \\ context is required in order to understand health promotion in prison and examines the potential for \\ empowerment, a cornerstone of health promotion practice, in high-security prison establishments. \\ Design/methodology/approach: Independent prison inspections, conducted by Her Majesty's \\ Inspectorate of Prisons for England and Wales (HMIP), form a critical element in how prisons are \\ assessed. Documentary analysis was undertaken on all eight high-security prison reports using \\ framework analysis. \\ Findings: Analysis revealed elements of prison life which were disempowering and antithetical to \\ health promotion. While security imperatives were paramount, there were examples where this \\ was disproportionate and disempowered individuals. The data shows examples where, even in \\ these high-security contexts, empowerment can be fostered. These were exemplified in relation to \\ peer approaches designed to improve health and where prisoners felt part of democratic processes \\ where they could influence change. \\ Practical implications: Both in the UK and internationally, there is a growing rhetoric for delivering \\ effective health promotion interventions in prison, but limited understanding about how to \\ operationalise this. This paper gives insight into how this could be done in a high-security prison \\ environment. \\ Originality/value: This is the first paper which looks at the potential for health promotion to be \\ embedded in high-security prisons. It demonstrates features of prison life which act to disempower \\ and also support individuals to take greater control over their health.
}

\section{Introduction}

There is a growing body of evidence surrounding the settings approach in health promotion, but critics have often argued that the settings approach has lacked nuanced analysis - often suggesting that a 'one size fits all' approach frequently used in schools, workplaces, hospitals and universities can overlook the differences even within settings that seem to share similar characteristics. Prisons remain settings of tremendous power inequalities (Symkovych, 2018), rendering empowerment, a primary construct for health promotion devoid of meaning or even obsolete. The extent to which this occurs, however, may differ based on the specific context of imprisonment and the position of health promotion vis-à-vis the prison and its security mandate has often been unclear (Woodall et al., 2013).

The discourse and policy surrounding the health promoting prison has been highlighted for failing to fully acknowledge the diversity that exists between prison contexts (Woodall, 2016). Some have suggested that a more detailed understanding of prison settings is recommended and more sensitive policy and practice which reflects the remit and function of the prison (Woodall, 2010). This seems critical given that the prison estate has such diversity in function, size and purpose. In England and Wales, the focus of this paper, the prison estate has a mixture of publicly and privately-run institutions; newly built prisons and others dating back to the Victorian era (Brown, 2018). In addition, after the publication of the Mountbatten Report in 1967 all adult male prisoners in England and Wales have been classified into four security categories. Prisoners who pose the most serious danger to the public, the police or to the security of the nation, are classified as category-A prisoners, whereas category-D prisoners are those who are trusted to serve their sentence in open conditions (Leech and Cheney, 2002). Category-A prisoners frequently pose significant danger to the public and accordingly are placed in high-security facilities. High-security prisons express the coercive power of the state in its most extreme form operating through using significant levels of control (Liebling, 2016). In England and Wales, there are eight high-security establishments all of 
which are run by the state - these are: Belmarsh; Frankland; Full Sutton; Long Lartin; Manchester; Wakefield; Whitemoor; and Woodhill.

Foucault (1977: p.202) suggested that the experience of prison life does not produce "homogenous effects". Open prisons, for instance, as opposed to high-security prisons, may enable more freedom, control and choice but limited exploration has fully ascertained this in relation to health outcomes. It is broadly recognised that, ideologically, health promotion is incongruous in a prison setting as these environments are seen to be "antithetical to the principles of health promotion rhetoric" (Smith, 2000: p.346). This, it could be assumed, is amplified in a high-security context where control must be heightened and the agency of prisoners minimised for public protection. Loss of freedom is inherently pathogenic, whilst prisons have to place to the fore concerns with public safety and thus with prison security (Woodall et al., 2013).

Nevertheless, there is a tension, as some evidence focussing on health promoting interventions suggests that long-stay prison institutions offer an ideal context for meaningful activity. The effectiveness of peer interventions addressing health need in prison settings, for example, was reported to be contingent on managing 'prisoner turnover', i.e. the rate at which prisoners arrive and then are released from institutions or relocated to another prison. Remand prisons and institutions that have high 'turnover' of prisoners can create instability and challenges in relation to the training and retention of peer deliverers. Clearly, lengthy training programmes may be appropriate in longer stay, high-security prisons containing less transient populations with reduced probability of imminent release or relocation to another institution (Woodall et al., 2015). In addition, Edgar et al. (2011a) commonly cited rapid prisoner turnover as a major obstacle for recruiting prison volunteers and engaging active citizenship.

Current understanding of whether values central to health promotion can be applied in the prison context, let alone the high-security prison estate, is largely unknown (Woodall et al., 2013). While there is no major consensus on what constitutes the primary values in health promotion, work has frequently identified empowerment as a cornerstone (Tilford et al., 2003; Woodall et al., 2012; Bunton and Macdonald, 1992). While empowering prisoners has never been an accepted pursuit in prison systems, even regarded as "morally questionable and politically dangerous" (The Aldridge Foundation and Johnson, 2008: p.2), there is a growing recognition that prisons should be "supportive and empowering" (de Viggiani et al., 2005: p.918). 'Empowerment' is still an idea of significance for health promotion and should be central to the development of the health promoting prison as originally outlined in consensus documents on health promotion in prison (WHO, 1995). Current understanding as to what works in regard to promoting health and well-being is not fully understood - mainly because of challenges in developing the evidence-base and conducting research in this context. Nonetheless, some have suggested that peer interventions; exercise and fitness; horticulture interventions; yoga, mindfulness and meditation; group psycho-education; creative arts for health; sexual health interventions and therapeutic communities are potentially beneficial (Woodall et al., 2019).

This paper seeks to analyse data from one year (2018) of inspection reports in eight long-term, highsecurity male prisons in England and Wales. Specifically, it explores whether empowerment as a critical value central to health promotion can be applied in a context where security and control can be expected to dominate the environment. It looks at the application of empowerment in prison and moreover those factors which demote empowerment in the high-security context. This paper is timely given the increased scrutiny of regulation and inspection in prisons, particularly in relation to health and well-being (Health and Social Care Committee House of Commons Education and Skills, 2018). Despite the focus on one jurisdiction, most countries have variations in regard to security 
classifications of prisons and, with this in mind, the implications for the health promoting prison concept internationally, particularly in Europe, where this issue is of increasing interest, is apparent.

A working definition of empowerment is required in order to identify issues within the prison context that facilitate and enable empowerment. Most definitions accept that empowerment is a complex process and it can occur at an individual, organisational or community level. This implies that empowerment is not only about people changing, but also about environmental, organisational and system change (Woodall et al., 2010). To this extent, Rappaport's (1987) view that empowerment is a process by which people, organzations and communities gain mastery over their affairs has been considered appropriate given that empowerment should be applied both at an individual and community-level.

\section{Methodology}

This research has adopted a methodology for analysing prison inspection reports which is discussed in greater depth elsewhere (Woodall and Freeman, 2019). The inspection reports were identified through the HMIP website (https://www.justiceinspectorates.gov.uk/hmiprisons/), a free to access resource in the public domain. Although independent inspections have been in existence for four decades (Bennett, 2014), reports online date back to January 2012. The rationale for sampling the latest reports from the high-security prison estate was to provide a contemporary perspective on activities being delivered. While this was a desk-based study of data in the public domain, the study protocol was reviewed by Leeds Beckett University ethics committee. Each of the high-security establishments varied in their geographical location; population density and the population profile in terms of the age of those serving sentences in the prisons; management structure; and healthcare delivery provider. However, consistently throughout the population, prisoners were generally serving prison sentences of 10 or more years. The focus of this paper was on male prison establishments, although future investigation should also examine women's facilities.

The entire inspection report was read and became familiar to the researcher. Prison inspectors work to a set of "expectations" relating to the level and quality of service that it expects to find in prisons (Reed and Lyne 1997). These 'expectations' are used to structure each prison inspection report. Data were analysed using Framework Analysis, which was considered an appropriate method given the applied nature of the study and the emphasis on reviewing policy and practice (Ritchie et al., 2003). The term 'framework' relates to the central part of the analytical process, that is, the development of a framework or matrix with which to systematically locate data sources. Concepts and themes in the data are then summarised and charted in the matrix. Care was taken to summarise but not to 'fragment' the data, which can occur when segments of text are divorced from the context in which they were originally stated. The matrix was constructed using four simple thematic categories - individual empowerment (facilitated); community empowerment (facilitated); individual empowerment (inhibited); community empowerment (inhibited). Data were identified within the report based on where individual or collective empowerment was interpreted (explicitly, though mainly implicitly) to have been presented and discussed in the reports. Once identified in the reports, the data were charted (where appropriate, direct extracts were taken from the report to retain original meaning) against these categories - after this stage, more nuanced themes under each thematic category were established and a narrative account summarising each of the themes was produced. These are presented in this paper.

\section{Findings}

This section reports analysis from all high security prison inspection reports which are freely available. It is organised under broad thematic categories, mirroring the salient points in the reports. The prisons have not been identified in the presentation of data. 


\section{Disempowering aspects of high-security prison life}

There was an overwhelming amount of data within prison inspection reports to suggest that the high-security prison environment was highly detrimental to levels of control and empowerment experienced by individuals. The following issues were most prominent in the data analysed.

Violence

Violence was commonplace, with reports in some prisons that this was increasing year on year. Many prisoners were reported to feel unsafe within the high-security estate:

"The prison was reasonably calm and well ordered. However, violence had increased and was now at a high level...About a quarter of prisoners in our survey said they felt unsafe at the time of our inspection."

"The number of assaults... had increased since our previous inspection and some incidents were serious"

There were many reports of violence, but few examples or indications about how this had been managed or addressed within the institutions. There were reports of significant acts of violence, including murder, and some assaults on prison staff and assaults by staff on prisoners:

"The population was challenging and presented many risks; there had been some very serious incidents of violence since our last inspection, including two murders. There had also been an act of concerted indiscipline, and assaults on staff had risen."

"...we found an alleged staff-on-prisoner assault that had not been properly investigated and an example of excessive use of force that had not previously been identified."

Disproportionate levels of control

The surveillance and security of the high-security prison was paramount, reflecting the serious nature of prisoners' offences within the establishments:

"[the prison] had stringent physical and procedural security arrangements, including extensive fencing, electronic gates and antihelicopter wire. These arrangements were appropriate for the risks posed by the population."

This included sophisticated technological solutions to the management of contraband which was in place in most of the establishments:

"Technology was being used to support efforts to manage violence and drug use at the prison, for example through the body scanner being piloted in reception."

There were, nonetheless, examples of disproportionate methods of control which exceeded what inspectors considered reasonable in the high-security estate. Much of these activities were degrading to individuals, many of which often focussed on the removal of clothing and stripsearching:

"A few practices were disproportionate, such as strip-searching all prisoners in reception and searching all mainstream prisoners in health care without meaningful risk assessment."

"...reception staff and managers told us that all prisoners were routinely strip-searched as part of release procedures which was disproportionate and disrespectful."

There were examples of prisoners being locked in their cell for periods of time deemed too lengthy and this was broadly condemned as unacceptable. The reasons for this were often unexplained, but were frequently discussed in relation to staffing and resources (discussed later):

"Prisoners spent nearly all day locked in their cells with nothing meaningful to do and there was still little in place to mitigate the detrimental effects of prolonged segregation."

Some inspection reports suggested prisoners were locked in their cell for 23 hours per day, although this number did vary between institutions: 
"...older prisoners who did not work were not routinely unlocked during the working day and we spoke to one 88-year-old who was only unlocked for two hours on most days."

\section{Resourcing and staffing}

Most prison reports stated that adequate resources and required staffing levels were compromised and this had an impact on the levels of support and care offered to the prisoner population. This had tangible impacts on the daily regime and the ability for prisoners to have adequate time out of their cells:

"...there was a significant shortage of frontline staff. It was being addressed, but had resulted in a severely depleted daily regime and regular redeployment of specialist staff to ensure that even a basic period of daily unlocking time could be given. We considered this issue had affected all four of our healthy prison tests, but was particularly detrimental to the area of purposeful activity"

Compromises to staffing not only impacted upon the basic regime or unlocking prisoners and ensuring that they were fed, but inevitably this compromised the ability to deliver specialist provision which may have made positive contributions to prisoners' long-term futures:

"Staffing shortages were affecting the range and quality of work being undertaken by the offender management unit, and many men had little, if any, contact with their offender supervisor."

"...staffing shortfalls meant the pre-release programme, which had included debt management work, had been suspended, and there was little direct support while prisoners were in custody."

\section{Psychological empowerment: encouraging a sense of control}

Notwithstanding the environmental context which demoted people's choice and control, there were several examples of interventions and programmes which actively sought to bolster prisoners' sense of control. The majority of the high-security estate was effective at delivering services to prisoners, many of which dealt which the issues of substance use and mental health:

"A psychologically led service supported men with mild to moderate problems, such as anxiety and depression. It included a good range of self-help material, group work and a range of individual therapies, such as counselling services"

The interventions, while not discussed in the inspection reports in terms of effectiveness, were often based on clinical models of support and often based on changing thinking and attitudes to behaviours and addictions.

While the data showed aspects of residential culture as being problematic and deleterious to prisoners feeling any sense of control, other aspects of prison life did provide positive opportunities. Two service areas were praised consistently in the reports. First, the chaplaincy service offered within the prisons were frequently cited as being exemplary in its ability to support individuals and maintain aspects of faith and resilience. In most prisons, the support offered by the chaplain covered all religious backgrounds and groups:

"The chaplaincy made a strong contribution to prison life through membership of management groups, regular visits to prisoners who were ill or distressed and meeting all new prisoners. They provided valued support to individual prisoners and staff who asked for pastoral care. The chaplaincy also organised a lay visitors' programme for prisoners who did not have visits from family or friends."

Second, the physical activity provision was routinely praised for allowing prisoners the opportunity to stay active should they chose to. The inspection reports did not allude to the extent to which facilities were actually used by prisoners, however: 
"There was a wide range of well-maintained PE facilities, which included a large multipurpose gym, two fitness rooms with a range of weights and cardiovascular equipment, and an all-weather football pitch. Prisoners also had access to training equipment on the accommodation wings."

\section{Community empowerment}

This section reports those areas of prison life which were suggested to enhance aspects of community empowerment - enabling prisoners to gain mastery over their wider affairs. Community empowerment can be regarded as a series of actions which progressively contribute to more organised community and social action within a prison context.

\section{Peer support}

The data suggested that community empowerment and support was at its strongest in relation to how prisoners acted to support each other; thereby addressing individuals' personal concerns and fostering a more conducive environment for help-seeking and sharing. Peer support workers were utilised and deployed by the vast majority of prisons in a myriad of ways, as exemplified in the following:

"Peer mentors trained by the Shannon Trust, which promotes literacy, also supported men well and assisted the librarians during opening hours."

"Peer supporters played a key role in helping new prisoners to settle in and were on hand throughout their stay on the first night centre."

In some prisons, it was clear that peer workers were seen as an extension of the prison workforce; trained and supported and contributing to intervention development:

"Peer supporters told us that they were well supervised and supported to deliver one-to-one interventions and work with DTS staff on designing new group programmes."

Moreover, in several prisons there were concerted efforts to expand the workforce and increase provision of peer workers.

"There was a good team of 14 Listeners (prisoners trained by the Samaritans to provide confidential and emotional support for their peers) and there were plans to train more prisoners."

Democratic rights and contribution to system change

One of the key areas where prisoners demonstrated attributes of empowerment and with the ability to contribute to system change was through democratic forums designed to encourage active participation and views on many aspects of the prison. The data revealed examples where prisoners could have a say in how the prison was run and this often included areas such as healthcare and catering. Exemplary practice was seen where senior prison staff chaired or were involved in the meetings with prisoners:

"Prisoner consultation was effective and purposeful. A prisoner consultation forum, usually chaired by the governor, met every month and considered an agenda decided by the prisoner forum members. Prisoner representatives told us that matters raised were addressed directly by managers, who attended meetings when matters concerning their areas of responsibility were discussed. Custodial managers also met wing representatives regularly to resolve local issues."

There were, however, some implications of tokenism whereby forums were held but actions suggested by the group not acted upon:

"Consultation arrangements were reasonable... Minutes of the monthly meetings indicated discussion across a wide range of areas but some issues were carried over from month to month with no resolution." 
In addition, some high-security prisons, while demonstrating commitment to the democratic rights of prisoners often failed to ensure that the perspectives of the most marginalised communities in the prison were heard. This was the case in relation to some foreign national prisoners and gay and bisexual prisoners:

"There were no forums for foreign nationals, for consultation, support and the opportunity to meet, to discuss their common issues with appropriate experts."

"There was insufficient support for gay and bisexual prisoners. Quarterly support meetings took place but there was no evidence of identified actions being addressed. We spoke to several gay prisoners who did not attend the forum and were not fully aware of what support was available."

\section{Working to address social determinants}

Although far from universal, there were indications that some prisons were genuinely concerned about the importance of education and training to enable longer-term transformation of prisoners' future lives. This was not only acting as an occupation while in prison to deter boredom, but also for the future of individuals once released. Clearly, given the length of sentence that many men were undertaking in the high-security estate, the likelihood of these skills remaining current and contemporary was limited:

"A broad range of education was offered, including: functional skills from entry level to level 2; several GCSE courses; distance learning; and an undergraduate programme run in conjunction with [a] University."

The majority of training offered within the prisons focussed on manual work, although did provide broader theoretical links on occasions:

"High-quality vocational training was provided in industrial cleaning, and food preparation and cooking, where teachers made clear links between practical work and theory."

\section{Discussion}

This paper sought to gain greater insight into the high security prison estate and to establish the extent to which empowerment - at an individual, organisational and community level - is evident in this setting. While inspectors are not explicit in their description or labelling of activities within the high-security prison as 'empowering' or 'disempowering', this study sought to analyse the data to understand how such a construct manifests in this specific context. Empowerment is important as, not only is it a cornerstone value of health promotion, but has clear linkages to improved health and well-being (Woodall et al., 2010). If health promotion is to be implemented in prison settings, then understanding how empowerment can be fostered and the disempowerment of prisoners minimised is critical. There has been a momentum shift at governmental levels for better and more effective health promotion in prisons (Health and Social Care Committee House of Commons Education and Skills, 2018), but practice continues to lag (Woodall, 2016). This paper offers insight into how to potentially operationalise health promotion in a specific type of prison - the highsecurity estate. This contribution is potentially of importance, as the evidence base on effective interventions to improve health and well-being in prison is largely unknown (Woodall et al., 2019) and moreover, current views of health promotion in this context tends to assume a 'one-size fits all' approach without the specificity of considering high-security contexts.

Previous research has utilised the analysis of prison inspection reports as a methodology to gain greater insight into prisons (Woodall and Freeman, 2019). This is not a common approach though, despite prison inspections taking place across various parts of the world. The view provided by HMIP is highly-valuable, given that they have access to all areas of an institution and can arrive unannounced (Hardwick 2016). Prison inspections draw on a range of data, including a confidential 
survey of a representative proportion of the prisoner population; prisoner focus groups; individual interviews carried out with staff and prisoners; documentation analysis; and observation by inspectors (Bennett 2014). It is a methodology which is recognised for its international excellence (Harding 2006). The importance of the inspection report has been long-standing and recognised, but there has recently been a re-emphasis on the power that inspection reports have in shaping policy and practice in prison health (Health and Social Care Committee House of Commons Education and Skills, 2018). That said, this paper is clear that it is reporting on the judgements and reporting of inspectors and indeed, it should be noted that some commentators have argued that inspection reports are overly negative and may fail to fully capture good practice in aspects of service delivery (Walsh, 2009).

By design, imprisonment removes elements of control and choice from individuals; at least those choices which might endanger the public and jeopardise the safe running of the institution (Pryor, 2001). Whilst the concept of control has rarely been investigated within the context of imprisonment, a body of work exists which has alluded to the removal of personal control as a result of imprisonment (Clemmer, 1940; Sykes, 1958; Goffman, 1968; Cohen and Taylor, 1972; Toch, 1977; Goodstein et al., 1984). The data demonstrates this clearly which is unsurprising given the highsecurity context and illustrated by physical and technological measures to ensure the safety of the institution and wider public. However, there were examples where control measures were not proportionate and undermined aspects of health promotion including individuals' sense of dignity. Lengthy periods of confinement are clearly unconducive to positive aspects of health and well-being. It was clear that in many cases, fundamental values within health promotion, such as control, choice and empowerment, were unfairly obstructed within prisons (Woodall et al., 2013). The analysis presented here was that there were levels of disempowerment that should not have been present in a system seeking to support prison populations.

Notwithstanding the discussion to date, the data also shows examples where, even in high-security contexts, empowerment can be fostered. Several of the interventions offered to prisoners were often designed to enable individuals to make alternate choices in relation to health and offending behaviours - these were often focused on improving aspects of self-esteem and self-efficacy established indicators of psychological empowerment (Koelen and Lindstrom, 2005). A further salient feature which provided opportunity for prisoners to establish a sense of broader control was the inclusion of individuals in democratic features of prison life. The benefits of such civic engagement and participation has been noted elsewhere (Cheney, 2008), but some evidence here that not all prisoners felt their voices were heard. In addition, the positive impact on the institutional culture and ethos as a result of peer interventions being delivered within prison settings was reported. This finding seems to be supported in some of the wider literature (Blanchette and Eljdupovic-Guzina, 1998; Cloyes et al. 2017; Edgar et al., 2011b; Loeb et al., 2013; Syed and Blanchette, 2000; Wright and Bronstein, 2007a; Wright and Bronstein, 2007b) whereby it has been suggested that peer interventions result in a more caring and humane atmosphere within the prison; can reduce volatility and can create more cohesion between staff and prisoners. It will be important to balance the value of peer workers against the reductions in staffing and resource in prisons. Peer workers offer significant value and are effective (Bagnall et al., 2015), but cannot replace the work of trained paid staff.

One of the cogent arguments for delivering health promotion in prison contexts is that many individuals in prison serve relatively short sentences and therefore positive interventions in the prison offer community dividends given the transient nature of the population. This argument, however, is slightly diluted in this environment whereby individuals serve longer sentences and the benefits to the wider public are less tangible. Humanitarian arguments about the treatment and support that people in prison should receive and creating prisons that are supportive and 
empowering, are important to modern and progressive views of imprisonment. The stark reality is that high-security prisons offer a prime environment for positive health intervention, but to date the opportunities are not being maximised and are being inhibited by a climate of under resourcing, disproportionate levels of control and violence.

\section{Conclusions}

Wacquant (2002: p.388) has cautioned against viewing prisons merely as "distortive and wholly negative" as the prison may also act as a "stabilizing and restorative force", especially for those at the bottom of society's hierarchy who may have faced significant disadvantage. While there are indications within the data that this may be the case, the deleterious impacts of prison life were clearly evident. This paper makes two clear contributions to improving health promotion in prison contexts. First, the disempowering nature of high-security prison life is perhaps inevitable given the absolute mandate to protect the public. That said, it was clear that the levels of disempowerment in some prisons was disproportionate and unnecessary. This should be curtailed. Second, there are clearly elements of prison life that foster empowerment and these should be embraced, continued and replicated where they can be.

Understanding control and power within a prison is crucial for understanding health promotion within settings (Green et al., 2000). Enabling people to take control over their lives and their wider health determinants is a critical feature of health promotion and plays a pivotal role within the empowerment discourse. WHO's explicit focus on health promotion and values such as enablement and empowerment have gradually been eroded (Woodall, 2016). Wider public perceptions about who is 'deserving' of support has created challenges in providing equivalent health services in prison (Baybutt et al., 2010), including health promotion where ideas such as the 'empowerment' of prisoners sit uneasy in parts of the public and political domain. The analysis shows examples where empowerment can be fostered in a high-security prison, but such positive examples are severely compromised by disempowering features such as violence and resource shortages. The paper suggests that health promotion strategies are possible in high-security prison contexts and that strategies to empower people in prison can work. However, there is clear evidence that such approaches can be diluted.

Evidence shows that prisons deal exceptionally well at managing disease and tackling public health outbreaks (Woodall and Freeman, 2019). However, the extent to which prisons foster salutogenic elements is highly debateable, especially given the data here which shows the negative impacts of prison life. The data demonstrates that empowerment can be fostered in a high-security context and that facets of prison life, such as democratic inclusion and peer support, may be initial hooks to develop more embedded interventions. More research is required to understand what interventions work in this particular context and moreover to focus on the female prison estate to enable more empowering and supportive prison environments to be realised.

\section{References}

Bagnall A-M, South J, Hulme C, et al. (2015) A systematic review of the effectiveness and costeffectiveness of peer education and peer support in prisons. BMC Public Health 15: 1-30.

Baybutt M, Hayton P and Dooris M. (2010) Prisons in England and Wales: an important public health opportunity? In: Douglas J, Earle S, Handsley S, et al. (eds) A reader in promoting public

health. Challenge and controversy. 2nd ed. Milton Keynes: Open University Press, 134-142.

Bennett J. (2014) Resisting the audit explosion: the art of prison inspection. The Howard Journal of Criminal Justice 53: 449-467.

Blanchette K and Eljdupovic-Guzina G. (1998) Results of a Pilot Study of the Peer Support Program for Women Offenders. Canada: Correctional Service of Canada 1-94.

Brown J. (2018) The prison estate. London: The House of Commons Library. 
Bunton R and Macdonald G. (1992) Health promotion. Disciplines and diversity, London: Routledge. Cheney D. (2008) Prisoners as citizens in a democracy. The Howard Journal of Criminal Justice 47: 134-145.

Clemmer D. (1940) The prison community, New York: Holt, Rinehart and Winston.

Cloyes, K.G., Rosenkranz, S., Supiano K.P., Berry, P.H., Routt, M., Llanque, S.M. \& Shannon-Dorcy, K. (2017). Caring to learn and learning to care: Inmate hospice volunteers and the delivery of prison end-of-life care. Journal of Correctional Health Care 23: 43-55.

Cohen S and Taylor L. (1972) Psychological survival. The experience of long-term imprisonment, Harmondsworth: Penguin.

de Viggiani N, Orme J, Powell J, et al. (2005) New arrangements for prison health care provide an opportunity and a challenge for primary care trusts. British Medical Journal 330: 918.

Edgar K, Jacobson J and Biggar K. (2011a) Time well spent: a practical guide to active citizenship and volunteering in prison. London: Prison Reform Trust.

Edgar K, Jacobson J and Biggar K. (2011b) Time Well Spent: A practical guide to active citizenship and volunteering in prison. Prison Reform Trust London: Prison Reform Trust.

Foucault M. (1977) Discipline and punish. The birth of the prison, Harmondsworth: Penguin.

Goffman E. (1968) Asylums: essays on the social situation of mental patients, Harmondsworth: Penguin.

Goodstein L, MacKenzie DL and Shotland RL. (1984) Personal control and inmate adjustment to prison. Criminology 22: 343-369.

Green LW, Poland BD and Rootman I. (2000) The settings approach to health promotion. In: Poland BD, Green LW and Rootman I (eds) Settings for health promotion. Linking theory and practice. Thousand Oaks: Sage, 1-43.

Health and Social Care Committee House of Commons Education and Skills. (2018) Prison health. Twelfth Report of Session 2017-19. London: House of Commons.

Koelen MA and Lindstrom B. (2005) Making healthy choices easy choices: the role of empowerment. European Journal of Clinical Nutrition 59: S10-S16.

Leech M and Cheney D. (2002) Prisons handbook, Winchester: Waterside Press.

Liebling A. (2016) High security prisons in England and Wales: principles and practice. In: Jewkes $Y$, Crewe B and Bennett J (eds) Handbook on prisons New York: Routledge, 477-496.

Loeb SJ, Hollenbeak CS, Penrod J, Smith C.A, Kitt-Lewis, E, and Crouse, SB. (2013) Care and companionship in an isolating environment: Inmates attending to dying peers. Journal of Forensic Nursing 9: 35-44.

Pryor S. (2001) The responsible prisoner: an exploration of the extent to which imprisonment removes responsibility unnecessarily and an invitation to change. London: HM Prison Service.

Rappaport J. (1987) Terms of empowerment/exemplars of prevention: toward a theory for community psychology. American Journal of Community Psychology 15: 121-148.

Ritchie J, Spencer L and O'Connor W. (2003) Carrying out qualitative analysis. In: Ritchie J and Lewis J (eds) Qualitative research practice. London: Sage, 219-262.

Smith C. (2000) Healthy prisons: a contradiction in terms? The Howard Journal of Criminal Justice 39: 339-353.

Syed F and Blanchette K. (2000) Results of an evaluation of the peer support program at Joliette Institution for women. Correctional Service of Canada.

Sykes GM. (1958) The society of captives: a study of a maximum security prison, New Jersey: Princeton University Press.

Symkovych A. (2018) Compromised power and negotiated order in a Ukrainian prison. The British Journal of Criminology 58: 200-217.

The Aldridge Foundation and Johnson M. (2008) The user voice of the criminal justice system. London: The Aldridge Foundation. 
Tilford S, Green J and Tones K. (2003) Values, health promotion and public health. Leeds: Centre for Health Promotion Research, Leeds Metropolitan University.

Toch H. (1977) Living in prison, New York: Free Press.

Wacquant L. (2002) The curious eclipse of prison ethnography in the age of mass incarceration. Ethnography 3: 371-398.

Walsh E. (2009) Prison health care: it's time to 'water the flowers'. British Journal of Nursing 18: 218218.

WHO. (1995) Health in prisons. Health promotion in the prison setting. Summary report on a WHO meeting, London 15-17 October 1995. Copenhagen: WHO.

Woodall J. (2010) Control and choice in three category-C English prisons: implications for the concept and practice of the health promoting prison. Unpublished PhD thesis. Faculty of Health. Leeds: Leeds Metropolitan University.

Woodall J. (2016) A critical examination of the health promoting prison two decades on. Critical Public Health 26: 615-621.

Woodall J, Dixey R and South J. (2013) Control and choice in English prisons: developing healthpromoting prisons. Health Promotion International 29: 474-482.

Woodall J and Freeman C. (2019) Promoting health and well-being in prisons: an analysis of one year's prison inspection reports. Critical Public Health: 1-12.

Woodall J, Freeman C. and Bowering, M. (2019) What works to promote health and wellbeing in prisons? A Rapid Evidence Assessment. Leeds: Leeds Beckett University.

Woodall J, Raine G, South J, et al. (2010) Empowerment \& health and well-being: evidence review. Leeds: Centre for Health Promotion Research, Leeds Metropolitan University.

Woodall J, South J, Dixey R, et al. (2015) Factors that determine the effectiveness of peer interventions in prisons in England and Wales. Prison Service Journal 219: 30-37.

Woodall J, Warwick-Booth L and Cross R. (2012) Has empowerment lost its power? Health Education Research 27: 742-745.

Wright KN and Bronstein L. (2007a) Creating decent prisons: A serendipitous finding about prison hospice. Journal of Offender Rehabilitation 44: 1-16.

Wright KN and Bronstein L. (2007b) Organizational Analysis of Prison Hospice. The Prison Journal 87: 391-407. 